Wim Willems*, Michael Altgen and Lauri Rautkari

\title{
A molecular model for reversible and irreversible hygroscopicity changes by thermal wood modification
}

https://doi.org/10.1515/hf-2019-0057

Received February 27, 2019; accepted July 1, 2019; previously published online August 14, 2019

Abstract: Heat treatment (HT) is a well-known means to reduce the equilibrium wood moisture content (EMC) at a specified relative humidity (RH). EMC is profoundly decreased by the loss of accessible hydroxyl groups $\left(\mathrm{OH}_{\text {acc }}\right)$ in the wood matrix by thermochemical reactions. However, the obtained EMC reduction after HT can be partly reversible, depending on the ability of the wood matrix polymers to fully mechanically relax during HT. We discuss the results of our earlier experimental study on the $\mathrm{OH}_{\text {acc }}$ content and the associated EMC decrease at $93 \%$ RH by a relaxation inhibiting dry-HT vs. a relaxation enabling wet-HT. New experimental results, showing that $\mathrm{OH}_{\text {acc }}$ does not significantly change during reversible EMC changes, are added to the discussion. This study quantitatively supports a molecular explanation of the reversible EMC, in which wood moisture is principally bound at sorption sites, composed of two functional groups, constituting a hydrogen-donor/acceptor pair, involving at least one $\mathrm{OH}_{\text {acc }}$ group. The irreversible part of EMC reduction is assigned to the thermochemical removal of $\mathrm{OH}_{\text {acc }}$ from the wood matrix. The reversible part is attributed to a process of wood polymer conformal rearrangements, bringing an isolated $\mathrm{OH}_{\text {acc }}$ group in proximity of another free hydrogen-bonding functional group, creating a site for water sorption.

Keywords: crosslinks, equilibrium moisture content, heat treatment, mechanical relaxation, sorption sites

\section{Introduction}

The equilibrium moisture content (EMC) of wood can be readily reduced by high-temperature exposure and

\footnotetext{
*Corresponding author: Wim Willems, FirmoLin, Grote Bottel $7^{\mathrm{b}}$, 5753 PE, Deurne, The Netherlands, e-mail: w.willems@firmolin.eu Michael Altgen and Lauri Rautkari: Department of Bioproducts and Biosystems, Aalto University, P.O. Box 16300, 00076 Aalto, Finland
}

drying, although this effect may be partly reversible, as can be verified by the application of consecutive wetting/ drying cycles (Obataya and Tomita 2002; Čermák et al. 2015; Altgen and Militz 2016; Obataya and Higashihara 2017; Tarmian and Mastouri 2019). The reversibility has been ascribed by these authors to a non-equilibrium arrangement of wood polymers in the cell wall after the heat treatment (HT). The presence of crosslinks or hydrogen-bonds formed during dry-HT hinders the relaxation of the cell wall polymers toward their thermodynamically most favorable arrangement. This relaxation hindrance in HT-wood may be lifted by a post-treatment of vacuum impregnation with water or by applying consecutive cycles of wetting and drying. In the wet-HT process, polymer relaxation is accomplished during HT, avoiding or reducing the EMC recovery after the HT process (Obataya et al. 2002; Altgen and Militz 2016). The possibility of a (partial) EMC recovery deserves a scientific study, as the EMC is regarded as a key parameter of wood modification (Ringman et al. 2014).

To study the EMC recovery mechanism in more detail, Scots pine sapwood samples were prepared in a wide range of HT severities, obtained by dry heating in atmospheric superheated steam vs. a hydrothermal treatment, both followed by an extraction of the water-soluble degradation products (Altgen et al. 2018b). The accessible hydroxyl group $\left(\mathrm{OH}_{\text {acc }}\right)$ content was measured by hydrogen-deuterium exchange (HDX) and correlated with EMC $_{93 \%}$, the EMC at first exposure to $93 \%$ relative humidity $(\mathrm{RH})$. In this way, we could compare the $\mathrm{EMC}_{93 \%}$ at each $\mathrm{OH}_{\text {acc }}$ content in relatively crosslinked (dry-HT) vs. soft (wet-HT) extractive-free matrices of thermally modified wood. These two extremes were considered to represent the unrelaxed state of as-produced dry heated thermally modified wood and the corresponding final state after full relaxation, without the potentially disturbing effect of residual degradation products in the cell walls.

In the present work, we aim to address some unanswered questions in our previous study: (a) Does the dry-HT sample EMC indeed increase after water leaching? (b) Why is the dry-HT sample not relaxed by the post-HT sample leaching treatment? (c) Does the $\mathrm{OH}_{\text {acc }}$ content change after relaxation? 


\section{Materials and methods}

\author{
Materials and heat treatment
}

Scots pine sapwood (Pinus sylvestris L.) was cut into blocks of $20 \times 20 \times 10(\mathrm{R} \times \mathrm{T} \times \mathrm{L}) \mathrm{mm}^{3}$. The samples were clear of heartwood, knots and macroscopic defects. The samples were oven-dried using a temperature sequence of $40,60,80$ and finally $105^{\circ} \mathrm{C}$, with each temperature being held for $24 \mathrm{~h}$, before the initial dry mass and dimensions were determined. The experimentally investigated sample was heated in an oven at atmospheric pressure with superheated steam to a peak temperature of $225^{\circ} \mathrm{C}$, which was held for $180 \mathrm{~min}$, before cooling the oven to room temperature. After production, the sample was dried and stored above silica gel at $25^{\circ} \mathrm{C}$ for at least 1 week in an exicator.

\section{Hydrogen-deuterium exchange (HDX) and $\mathrm{EMC}_{93 \%}$}

$\mathrm{OH}_{\text {acc }}$ were quantified in a DVS apparatus (DVS ET, Surface Measurement Systems, London, UK) with a measuring accuracy of $0.1 \mu \mathrm{g}$ and a gas flow of $200 \mathrm{~cm}^{3} \mathrm{~min}^{-1}$ at $25^{\circ} \mathrm{C}$ during the measurement. Samples that were cut from the same slat before HT were used. Approximately $20 \mathrm{mg}$ of material was taken from the middle of each sample using a razor blade.

For HDX the following sequence was applied: (1) determination of oven-dry weight after heating at $60^{\circ} \mathrm{C}$ for $6 \mathrm{~h}$ followed by cooling to $25^{\circ} \mathrm{C}$ for $2 \mathrm{~h}$; (2) exposure to a set point $\mathrm{RH}$ of $95 \% \mathrm{RH}$ using $\mathrm{D}_{2} \mathrm{O}$ vapor for $12 \mathrm{~h}$; and finally (3) the determination of oven-dry weight as done in step (1). The dry $\mathrm{N}_{2}$ flow was kept constant at $200 \mathrm{~cm}^{3} \mathrm{~min}^{-1}$. $\mathrm{OH}_{\text {acc }}$ was calculated from the relative dry mass increase by HDX, assuming that each accessible $\mathrm{OH}$ group exchanges its ${ }^{1} \mathrm{H}$ atom for a ${ }^{2} \mathrm{H}(\mathrm{D})$, increasing the initial dry mass $\mathrm{m}_{0}$ by $1.00616 \mathrm{~g}$ per mole of HDX, to a deuterated dry mass $\mathrm{m}_{\mathrm{OD}}$

$$
\mathrm{OH}_{\mathrm{acc}}=\frac{\mathrm{m}_{\mathrm{oD}}-\mathrm{m}_{0}}{1.00616 \mathrm{~m}_{0}} \mathrm{~mol} \mathrm{~g}^{-1}
$$

For the determination of the EMC with $\mathrm{H}_{2} \mathrm{O}$, the same sequence was applied, except that $\mathrm{H}_{2} \mathrm{O}$ vapor was used in step (2) and that step (3) was omitted. When using $\mathrm{H}_{2} \mathrm{O}$ vapor, the measured $\mathrm{RH}$ was ca. $93 \%$. However, when using $\mathrm{D}_{2} \mathrm{O}$ vapor, the measured $\mathrm{RH}$ was much lower (ca. $87 \% \mathrm{RH}$ ) than the set point RH. It should be noted that the device was not calibrated for $\mathrm{D}_{2} \mathrm{O}$, but for $\mathrm{H}_{2} \mathrm{O}$ vapor, which results in erratic readings of the humidity probe when using $\mathrm{D}_{2} \mathrm{O}$. The absolute EMC values for $\mathrm{D}_{2} \mathrm{O}$ and $\mathrm{H}_{2} \mathrm{O}$ vapor should, thus, not be directly compared to one another. The respective EMCs were calculated from the masses $\mathrm{m}_{\mathrm{H}_{2} \mathrm{O}}$ and $\mathrm{m}_{\mathrm{D}_{2} \mathrm{O}}$ at the end of the moistening stages

$$
\begin{aligned}
& \mathrm{EMC}_{\mathrm{H}_{2} \mathrm{O}}=\frac{\mathrm{m}_{\mathrm{H}_{2} \mathrm{O}}-\mathrm{m}_{0}}{18.0153 \mathrm{~m}_{0}} \mathrm{~mol} \mathrm{H}_{2} \mathrm{O} \mathrm{g}^{-1} \\
& \mathrm{EMC}_{\mathrm{D}_{2} \mathrm{O}}=\frac{\mathrm{m}_{\mathrm{D}_{2} \mathrm{O}}-\mathrm{m}_{\mathrm{OD}}}{20.0276 \mathrm{~m}_{0}} \mathrm{~mol} \mathrm{D}_{2} \mathrm{Og}^{-1}
\end{aligned}
$$

The maximum absolute random errors by DVS are estimated at $0.2 \%$ EMC (Glass et al. 2018), corresponding to $0.11 \mathrm{mmol} \mathrm{H}_{2} \mathrm{O} \mathrm{g}^{-1}$ and $0.10 \mathrm{mmol} \mathrm{D}_{2} \mathrm{O} \mathrm{g}^{-1}$, and $0.16 \mathrm{mmol} \mathrm{g}^{-1}$ in $\mathrm{OH}_{\text {acc }}$ by statistical analysis of data from our previous study (Altgen et al. 2018b).

\section{$\mathrm{H}_{2} \mathrm{O}$ and DMSO soak procedures}

The adopted $\mathrm{H}_{2} \mathrm{O}$ soak treatment procedure consisted of 5 days soaking in deionized water of the wood sample and subsequent drying in an exicator above silica gel. A dimethyl sulfoxide (DMSO) treatment procedure consisted of 5 days soaking in DMSO, 5 days washing in daily changed water and subsequent drying in a desiccator above silica gel. One sample was exposed to the following EMC measurement steps:

A1. Oven-dry weight and $\mathrm{EMC}_{\mathrm{H}_{2} \mathrm{O}}$

A2. $\mathrm{H}_{2} \mathrm{O}$ soak treatment

A3. Oven-dry weight and $\mathrm{EMC}_{\mathrm{H}_{2} \mathrm{O}}$

A4. DMSO soak treatment

A5. Oven-dry weight and $\mathrm{EMC}_{\mathrm{H}_{2} \mathrm{O}}$

Another sample was exposed to the following HDX measurement steps:

B1. HDX with $\mathrm{EMC}_{\mathrm{D}_{2} \mathrm{O}}$ determination

B2. $\mathrm{H}_{2} \mathrm{O}$ soak treatment

B3. HDX with $\mathrm{EMC}_{\mathrm{D}_{2} \mathrm{O}}$ determination

B4. DMSO soak treatment

B5. $\mathrm{HDX}$ with $\mathrm{EMC}_{\mathrm{D}_{2} \mathrm{O}}$ determination.

\section{Results and discussion}

An EMC recovery after soaking of dry-HT wood, known from the literature (Obataya and Tomita 2002; Altgen and Militz 2016), is observed in the $\mathrm{EMC}_{\mathrm{H}_{2} \mathrm{O}}$ as well as the $\mathrm{EMC}_{\mathrm{D}_{2} \mathrm{O}}$ changes (lines 1 and 2 in Table 1 ). EMC with $\mathrm{D}_{2} \mathrm{O}$ is systematically lower than $\mathrm{H}_{2} \mathrm{O}$; however, after soaking the relative difference is diminished. This trend is continued after soaking in DMSO, a strongly polar wood-swelling liquid (Mantanis et al. 2009), practically removing all differences between $\mathrm{H}_{2} \mathrm{O}$ and $\mathrm{D}_{2} \mathrm{O}$ (line 3 in Table 1). The soak treatments in $\mathrm{H}_{2} \mathrm{O}$ cause a small dry mass loss (ML), which is further increased by soaking in DMSO and subsequent washing with $\mathrm{H}_{2} \mathrm{O}$. The progressively swollen wood matrix promotes the release of trapped degradation products that cannot evaporate under dry-HT process conditions, consistent with other studies (Hofmann et al. 2013; Wentzel et al. 2018).

For the first time, $\mathrm{OH}_{\text {acc }}$ has been measured before and after matrix relaxation, during which the EMC is significantly increased. $\mathrm{OH}_{\text {acc }}$ appears slightly decreased, which may be attributed to the loss of dry mass (\%ML) from the soak treatments (Altgen et al. 2018b). All measured $\mathrm{OH}_{\text {acc }}$ are larger than $9.20 \pm 0.16 \mathrm{mmol} \mathrm{g}^{-1}$, the value found in our previous study for the unrelaxed $225^{\circ} \mathrm{C}$ dry-HT wood sample. This may be attributed either to the sensitivity of the $\mathrm{OH}_{\text {acc }}$ for the new dry weight measurement procedure, or to sample-to-sample variation.

It is generally accepted that thermal wood modification leads to a reduction in EMC, at least in part, ascribed to the loss of $\mathrm{OH}$ groups from the wood matrix. However, quantitative experimental studies relating EMC to the 
Table 1: Effect of water and DMSO soak on $225^{\circ} \mathrm{C}$ dry-HT.

\begin{tabular}{|c|c|c|c|c|c|}
\hline & \multirow[b]{2}{*}{$\begin{array}{r}\mathrm{OH}_{\mathrm{acc}} \pm 0.16 \\
\left(\mathrm{mmol} \mathrm{g}^{-1}\right)\end{array}$} & \multicolumn{2}{|r|}{$\mathrm{H}_{2} \mathrm{O}$} & \multicolumn{2}{|r|}{$\mathrm{D}_{2} \mathrm{O}$} \\
\hline & & $\begin{array}{l}\mathrm{EMC} \pm 0.11 \\
\left(\mathrm{mmol} \mathrm{g}^{-1}\right)\end{array}$ & ML (\%) & $\begin{array}{l}\mathrm{EMC} \pm 0.10 \\
\left(\mathrm{mmol} \mathrm{g}^{-1}\right)\end{array}$ & ML (\%) \\
\hline (1) After dry-HT & 9.63 & 8.45 & - & 7.20 & - \\
\hline (2) After $\mathrm{H}_{2} \mathrm{O}$ soak & 9.47 & 9.72 & 1.47 & 8.79 & 1.24 \\
\hline (3) After DMSO soak & 9.28 & 11.46 & 4.30 & 11.31 & 4.39 \\
\hline
\end{tabular}

$\mathrm{ML}(\%)$ is the mass loss measured during the $\mathrm{A} 3$ and $\mathrm{A} 5$ steps, relative to the $\mathrm{A} 1$ step. $\mathrm{EMC}_{\mathrm{H}_{2} \mathrm{O}}$ are measured in the $\mathrm{A} 1, \mathrm{~A} 3$ and $\mathrm{A} 5$ steps. $\mathrm{OH}$ acc and $\mathrm{EMC}_{\mathrm{D}_{2} \mathrm{O}}$ are measured in the $\mathrm{B} 1, \mathrm{~B} 3$ and $\mathrm{B} 5$ steps.

content of hydroxyl groups are very scarce. The HDX method has become an important tool in determining the $\mathrm{OH}$ content, as it only counts the relevant $\mathrm{OH}$ groups in moisture sorption that are accessible by water molecules. However, Lindh et al. (2016) showed experimentally that the $\mathrm{OH}(3)$ group, associated with the $\mathrm{C} 3$-atom in the pyranose units, of cellulose cannot be deuterated, whereas the molecular dynamics simulation results of these authors indicated a retained hydrogen-bond ability of the $\mathrm{OH}(3)$ group with water molecules. On the other hand, quantitative experimental data on the occupancy of water molecules at the $\mathrm{OH}(3)$ groups of hydrated cellulose are still lacking. Moreover, hidden $\mathrm{OH}(3)$ groups (missed by HDX) in dry-HT wood are not expected to influence the conclusions from our main experiment, the measurement of $\mathrm{OH}_{\text {acc }}$ change by matrix relaxation.

Getting reliable results from the adopted gravimetric HDX method requires enough reaction time with $\mathrm{D}_{2} \mathrm{O}$ and very accurate dry mass measurements before and after HDX. The ratio between the determined EMC and $\mathrm{OH}_{\text {acc }}$ for the pine reference sample gives an occupancy of about $1 \mathrm{~mol}$ of water per mole of $\mathrm{OH}_{\text {acc }}$ at ca. 93\% RH (Figure 1, closed circle), consistent with independently estimated values for amorphous cellulose by Berthold et al. (1996) and for wood by Willems (2014). Note that an occupancy of 1.0 is rather circumstantial, in view of the large slope of the water sorption isotherm between $90 \%$ and $100 \% \mathrm{RH}$. The found $\mathrm{OH}_{\text {acc }}$ content of $10.3 \mathrm{mmol} \mathrm{g}^{-1}$ for the leached pine wood control sample is somewhat larger than reported values of $9.0 \mathrm{mmol} \mathrm{g}^{-1}$ for spruce (Picea abies L.) (Thybring et al. 2017), 7.5-9.5 mmol g-1 for birch (Betula pendula L.) (Popescu et al. 2014), 7.5 and $8.1 \mathrm{mmol} \mathrm{g}^{-1}$ for sesendok (Endospermum malaccense Benth. ex Müll.Arg.) and acacia (Acacia mangium Willd.) (Rautkari et al. 2013) and $6.8 \mathrm{mmol} \mathrm{g}^{-1}$ for Styrax tonkinensis (Pierre) Craib ex Hartwich (Phuong et al. 2007). On the other hand, $\mathrm{OH}_{\text {acc }}$ contents above $10 \mathrm{mmol} \mathrm{g}^{-1}$ have been observed for unmodified pine and spruce (Kymäläinen et al. 2015, 2018).

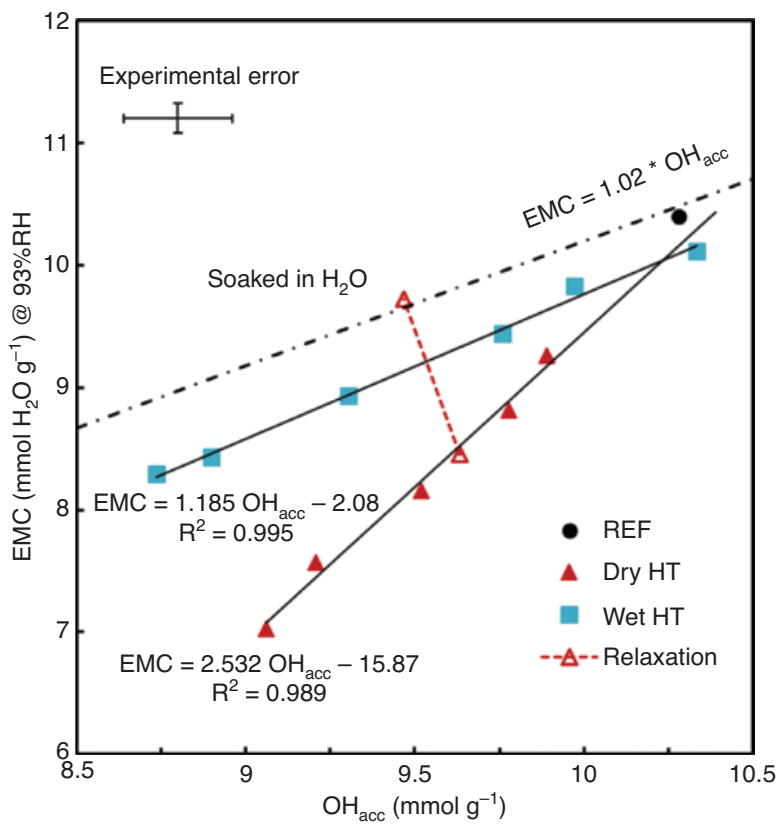

Figure 1: $\mathrm{EMC}_{93 \%}$ vs. $\mathrm{OH}_{\text {acc }}$ content of dry-HT (triangles), wet-HT (squares) and control sample (circle): data from Altgen et al. (2018b).

The open triangles represent the water soaking relaxation treatment for dry-HT sample (present study).

\section{Relaxation effect by water soaking dry-HT wood}

Our previous results (Figure 1) confirmed that dry-heating causes a much larger EMC decrease at first 93\% RH exposure than a hydrothermal treatment at the same modification level, as reported by Obataya et al. (2002) on spruce and Altgen and Militz (2016) on beech. The differences between the EMC of dry-HT and wet-HT remain in alternative correlations with the dry ML or the oxygen-to-carbon atomic ratio (Altgen et al. 2018b). Based on a molecular model of Willems (2018), which will be further elaborated in the present study, and the experimental observations of Obataya et al. (2002) and Altgen and Militz (2016), it was 
speculated that the dry-HT line would change after relaxation of the dry-HT material, by an EMC gain of each dry-HT point toward the wet-HT line without change of $\mathrm{OH}_{\text {acc }}$ (Altgen et al. 2018b). This is reasonably confirmed by our data on $\mathrm{EMC}$ and $\mathrm{OH}_{\text {acc }}$ before and after water soaking the dry-HT $225^{\circ} \mathrm{C}$ sample, plotted in Figure 1. The expected invariance of $\mathrm{OH}_{\text {acc }}$ is not perfect, because of the loss of cell wall material by soaking (Table 1 , ML values).

While DVS measurements appear to be well-repeatable, resulting in high $\mathrm{R}^{2}$ coefficients of determination of the regressions (Figure 1), Glass et al. (2018) show that there are systematic errors in the estimated dry masses and EMCs. Most importantly, small deviations in the dry mass before and after HDX influence the calculated $\mathrm{OH}_{\text {acc }}$ sensitively. As the development of advanced methods for accurate dry mass determination from the DVS curves is still on-going, we adopted an elevated oven-drying temperature at $60^{\circ} \mathrm{C}$ in the DVS apparatus in our current experiments, instead of $25^{\circ} \mathrm{C}$ in the earlier studies. This change of drying procedure appears to cause a shift in $\mathrm{OH}_{\text {acc }}$ by $+0.5 \mathrm{mmol} \mathrm{g}^{-1}$. Moreover, the lower dry weights achieved by this procedure cause a systematic EMC increase. Hence, the position of the included relaxation data points in Figure 1 may not be accurately aligned with the data points from our previous study. We note that simulations indicate that the ratio between the regression lines for the dry-HT and wet-HT is around 2.0, unaffected by the precise method of dry mass determination.

Remarkably, the applied leaching treatment in the previous study (Altgen et al. 2018b) did not bring about the relaxation effect, in contrast to a similar water soaking procedure in the present study. The main difference between the two cases is that the soaking procedure in the previous study was applied to the sample blocks instead of the much smaller DVS samples.

\section{Nature of the EMC effect of relaxation in dry-HT wood}

Qualitatively, the change in EMC of dry-HT wood after soaking is consistent with a wood polymer relaxation as suggested by earlier authors (Obataya and Tomita 2002; Altgen and Militz 2016). How the relaxation phenomenon physically affects the EMC has not been established yet.

The nearly invariant $\mathrm{OH}_{\text {acc }}$ with the water and DMSO soaking treatments rules out any explanation of an EMC gain by a correlated increase in $\mathrm{OH}_{\text {acc }}$. The observed ML after the water and DMSO soak, from the release of trapped cell wall degradation products, could be considered to play a potential role in water absorption volume exclusion (cell wall bulking). It is known that bulking of the cell wall by acetylation of $\mathrm{OH}_{\text {acc }}$ groups does reduce $\mathrm{OH}_{\text {acc }}$ to a lesser relative extent than the EMC (Popescu et al. 2014). Bulking does not shield nearby $\mathrm{OH}$ groups, but it controls the maximum number of $\mathrm{OH}_{\text {acc }}$ that can be active simultaneously (Willems 2018). This would in principle allow bulking to diminish EMC without changing $\mathrm{OH}_{\text {acc, }}$, although the attainable EMC reduction by bulking with the observed small ML remains to be quantitatively verified.

Dry-HT provides the most favorable conditions for crosslinking by condensation reactions, compared to wet-HT (Altgen et al. 2018a). This is confirmed by a significantly lower maximum swelling of dry-HT wood by water saturation, compared to wet-HT (Obataya et al. 2002; Altgen et al. 2016, 2018b). Engelund et al. (2013) discussed the function of such crosslinks as swelling restraints controlling the EMC over the entire hygroscopic range (0-95\% RH). The thermodynamic interaction of volume expansion (moisture swelling) against stresses imposed by mechanical restraints (matrix rigidity) has been theoretically described by Barkas (1949) and Willems (2014). Using the theory of the latter, relaxation would release a rather high amount (about $7 \mathrm{MPa}$ ) of stress to explain the reversible part of the EMC in the $225^{\circ} \mathrm{C}$ dry-HT sample. It also seems unlikely that the highly non-linear effect of stress on EMC (Willems 2014) and the variability of cell wall stiffness (Wagner et al. 2013) would result in a strictly $\mathrm{OH}_{\text {acc }}$-linear EMC deviation between dry-HT and wet-HT (Figure 1).

\section{A molecular model of the moisture sorption sites in wood}

The missing link between EMC and (the relaxation of) mechanical stress might be found in the molecular structure of moisture sorption sites in wood. Willems (2018) considered that the maximum hydrogen-bond enthalpy between $\mathrm{H}_{2} \mathrm{O}$ and an $\mathrm{OH}_{\text {acc }}$ group $\left(20-25 \mathrm{~kJ} \mathrm{~mol}^{-1}\right)$ is about half the amount needed to explain the wood-water bond enthalpy $\left(>44 \mathrm{~kJ} \mathrm{~mol}^{-1}\right)$. Hence, isolated water molecules or small water clusters were argued to be bound by pairs of $\mathrm{OH}_{\text {acc }}$ groups, but it is now considered that moisture sorption sites may alternatively be formed by pairing of an $\mathrm{OH}_{\text {acc }}$ group with any type of hydrogen-accepting oxygen-containing group (Guo et al. 2016) (Figure 2). Relaxation may enter the model as a necessary mechanism to enable the translocation of an isolated $\mathrm{OH}_{\text {acc }}$ group toward another hydrogen-bonding functional group to form a pair for moisture sorption. 


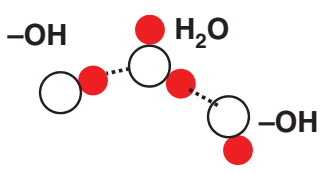

a

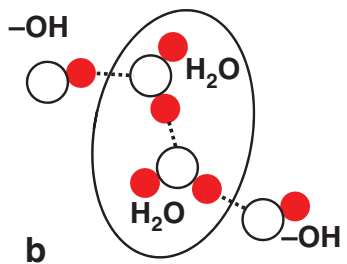

C

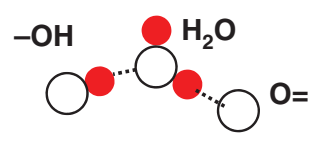

Figure 2: Proposed sorption sites for water, composed of pairs of hydrogen-bonding functional groups, involving at least one $\mathrm{OH}$ group: (a) water molecule between two $\mathrm{OH}$ groups; (b) water dimer cluster between two $\mathrm{OH}$ groups; (c) water molecule between one $\mathrm{OH}$ and one carbonyl group $(\mathrm{O}=)$.

White disks: oxygen atoms, red disks: hydrogen atoms. Dotted lines: hydrogen bonds.

The model does not only account for the correct magnitude of the binding enthalpy of water to wood, it also explains why some of the $\mathrm{OH}_{\text {acc }}$ groups in isolation cannot contribute to moisture sorption, despite being accessible. An $\mathrm{OH}_{\text {acc }}$ group is "inactive" when it is not paired for moisture sorption. The thermally induced disorder and destruction in the wood matrix during HT might be expected to leave some functional groups isolated, requiring a matrix relaxation to re-arrange them into active pairs for moisture sorption (Figure 3).

Figures 2 and 3 show the essence of the proposed moisture sorption model. Single water molecules or small water clusters can bind to sorption sites, constituted by two (H-donor/acceptor pair) functional groups. Such pairs are schematically drawn by ellipses in Figure 3 . The pairs can change nearby partners. When HT randomly removes an active functional group, the remaining free partner can recombine with a nearby functional group, leaving another functional group without partner. This effectively diffuses free hydrogen-bonding functional groups throughout the wood matrix, with minimal conformal polymer movements, until they meet and combine into new pairs.

The abundance of crosslinks in dry-HT wood and oven-dry conditions during the dry-HT process are thought to severely hinder the necessary polymer movements for the recombination mechanism. In contrast, the moist conditions and absence of crosslinks in wood in the wet-HT process optimally enable the recombination mechanism. Consequently, wet-HT wood is in the final relaxed state when it leaves the HT reactor, whereas dry-HT wood remains unrelaxed, making the latter susceptible to a post-production relaxation with an associated EMC increase (Figure 3).

Interestingly, the ratio between the two measured slopes of the dry-HT and wet-HT lines in Figure 1 is equal to 2 within $1 \sigma$ deviation $(2.1 \pm 0.2)$, which the model of Figure 3 can explain by the recovery of one sorption site pair (wet-HT) for every two lost site pairs in the unrelaxed matrix (dry-HT).

During the proposed relaxation process (Figure 3), the $\mathrm{OH}_{\text {acc }}$ content is not subject to change, as is reasonably confirmed by comparing the $\mathrm{OH}_{\text {acc }}$ measurements before and after water soaking.

\section{Conclusions}

The water soak procedure on small as-produced dry-HT wood samples in the present research appears effective in accomplishing relaxation, in contrast to the leach procedure applied to larger as-produced wood blocks in the previous research. The effect of partial recovery of the EMC

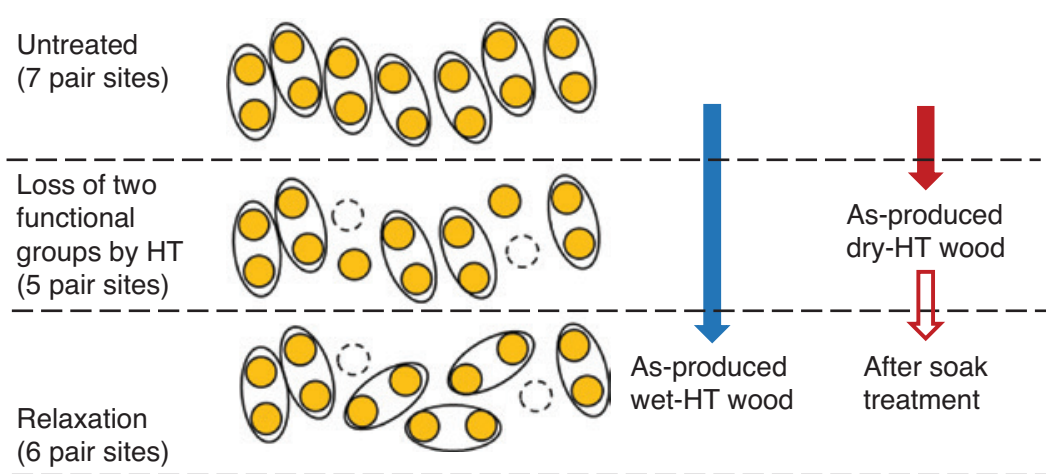

Figure 3: Schematic representation of the evolution of pair sites after HT.

Re-arrangement during relaxation recovers one pair for every two pairs lost initially by HT. Wet-HT wood completes the relaxation stage during production. Dry-HT wood remains unrelaxed after production, until water soaking. 
change by dry-HT was confirmed by water soaking, it did not significantly change $\mathrm{OH}_{\text {acc }}$.

The presented molecular model of wood moisture sorption comprehensively explains the different behavior of wet-HT and dry-HT wood, with respect to the reversible and irreversible EMC changes in as-produced thermally modified wood.

Author contributions: All the authors have accepted responsibility for the entire content of this submitted manuscript and approved submission.

Research funding: None declared.

Employment or leadership: None declared.

Honorarium: None declared.

\section{References}

Altgen, M., Militz, H. (2016) Influence of process conditions on hygroscopicity and mechanical properties of European beech thermally modified in a high-pressure reactor system. Holzforschung 70:971-979.

Altgen, M., Hofmann, T., Militz, H. (2016) Wood moisture content during the thermal modification process affects the improvement in hygroscopicity of Scots pine sapwood. Wood Sci. Technol. 50:1181-1195.

Altgen, M., Uimonen, T., Rautkari, L. (2018a) The effect of de-and re-polymerization during heat-treatment on the mechanical behavior of Scots pine sapwood under quasi-static load. Polym. Degrad. Stab. 147:197-205.

Altgen, M., Willems, W., Hosseinpourpia, R., Rautkari, L. (2018b) Hydroxyl accessibility and dimensional changes of Scots pine sapwood affected by alterations in the cell wall ultrastructure during heat-treatment. Polym. Degrad. Stab. 152:244-252.

Barkas, W.W. The Swelling of Wood Under Stress. H.M.S.O., London, 1949.

Berthold, J., Rinaudo, M., Salmén, L. (1996) Association of water to polar groups; estimations by an adsorption model for lignocellulosic materials. Colloids Surf. A 112:117-129.

Čermák, P., Rautkari, L., Horáček, P., Saake, B., Rademacher, P., Sablík, P. (2015) Analysis of dimensional stability of thermally modified wood affected by re-wetting cycles. BioResources 10:3242-3253.

Engelund, E.T., Thygesen, L.G., Svensson, S., Hill, C.A.S. (2013) A critical discussion of the physics of wood-water interactions. Wood Sci. Technol. 47:141-161.

Glass, S.V., Boardman, C.R., Thybring, E.E., Zelinka, S.L. (2018) Quantifying and reducing errors in equilibrium moisture content measurements with dynamic vapor sorption (DVS) experiments. Wood Sci. Technol. 52:909-927.

Guo, X., Qing, Y., Wu, Y., Wu, Q. (2016) Molecular association of adsorbed water with lignocellulosic materials examined by micro-FTIR spectroscopy. Int. J. Biol. Macromol. 83:117-125.

Hofmann, T., Wetzig, M., Rétfalvi, T., Sieverts, T., Bergemann, H., Niemz, P. (2013) Heat-treatment with the vacuum-press dewatering method: chemical properties of the manufactured wood and the condensation water. Eur. Wood Wood Prod. 71:121-127.

Kymäläinen, M., Rautkari, L., Hill, C.A.S. (2015) Sorption behaviour of torrefied wood and charcoal determined by dynamic vapour sorption. J. Mater. Sci. 50:7673-7680.

Kymäläinen, M., Mlouka, S.B., Belt, T., Merk, V., Liljeström, V., Hänninen, T., Uimonen, T., Kostiainen, M., Rautkari, L. (2018) Chemical, water vapour sorption and ultrastructural analysis of Scots pine wood thermally modified in high-pressure reactor under saturated steam. J. Mater. Sci. 53:3027-3037.

Lindh, E.L., Bergenstråhle-Wohlert, M., Terenzi, C., Salmén, L., Furó, I. (2016) Non-exchanging hydroxyl groups on the surface of cellulose fibrils: the role of interaction with water. Carbohydr. Res. 434:136-142.

Mantanis, G., Young, R., Rowell, R. (2009) Swelling of wood. Part II. Swelling in organic liquids. Holzforschung 48:480-490.

Obataya, E., Higashihara, T. (2017) Reversible and irreversible dimensional changes of heat-treated wood during alternate wetting and drying. Wood Sci. Technol. 51:739-749.

Obataya, E., Tomita, B. (2002) Hygroscopicity of heat-treated wood II. Reversible and irreversible reductions in the hygroscopicity of wood due to heating. Mokuzai Gakkaishi 48:288-295.

Obataya, E., Higashihara, T., Tomita, B. (2002) Hygroscopicity of heat-treated wood III. Effect of steaming on the hygroscopicity of wood. Mokuzai Gakkaishi 48:348-355.

Phuong, L.X., Takayama, M., Shida, S., Matsumoto, Y., Aoyagi, T. (2007) Determination of the accessible hydroxyl groups in heat-treated Styrax tonkinensis (Pierre) Craib ex Hartwich wood by hydrogen-deuterium exchange and ${ }^{2} \mathrm{H}$ NMR spectroscopy. Holzforschung 61:488-491.

Popescu, C.M., Hill, C.A.S., Curling, S., Ormondroyd, G., Xie, Y. (2014) The water vapour sorption behaviour of acetylated birch wood: how acetylation affects the sorption isotherm and accessible hydroxyl content. J. Mater. Sci. 49:2362-2371.

Rautkari, L., Hill, C.A.S., Curling, S., Jalaludin, Z., Ormondroyd, G. (2013) What is the role of the accessibility of wood hydroxyl groups in controlling moisture content? J. Mater. Sci. 48: 6352-6356.

Ringman, R., Pilgård, A., Brischke, C., Richter, K. (2014) Mode of action of brown rot decay resistance in modified wood: a review. Holzforschung 68:239-246.

Tarmian, A., Mastouri, A. (2019) Changes in moisture exclusion efficiency and crystallinity of thermally modified wood with aging. IForest 12:92-97.

Thybring, E.E., Thygesen, L.G., Burgert, I. (2017) Hydroxyl accessibility in wood cell walls as affected by drying and re-wetting procedures. Cellulose 24:2375-2384.

Wagner, L., Bader, T.K., Auty, D., de Borst, K. (2013) Key parameters controlling stiffness variability within trees: a multiscale experimental-numerical approach. Trees Struct. Func. 27:321-336.

Wentzel, M., Altgen, M., Militz, H. (2018) Analyzing reversible changes in hygroscopicity of thermally modified eucalypt wood from open and closed reactor systems. Wood Sci. Technol. 52:889-907.

Willems, W. (2014) The water vapor sorption mechanism and its hysteresis in wood: the water/void mixture postulate. Wood Sci. Technol. 48:499-518.

Willems, W. (2018) Hygroscopic wood moisture: single and dimerized water molecules at hydroxyl-pair sites? Wood Sci. Technol. 52:777-791. 